\title{
DESCRIÇÃO DE HEXAPANOPEUS HEBLINGI SP.N. (CRUSTACEA, DECAPODA, BRACHYURA, XANTHIDAE) DO LITORAL BRASILEIRO ${ }^{1}$
}

\author{
Misael Domingues Rodrigues ${ }^{2}$ \\ Jayme de Loyola e Silva ${ }^{3}$
}

\begin{abstract}
Description of Hexapanopeus heblingl SP.N. (CRUStacen, DeCaPoda, BRACHYURA, XANTHIDAE) FROM BRAZILIAN LITTORAL. Hexapanopeus heblingi sp.n. is described in base of an adult male reared in the laboratory. This species of crab is typic

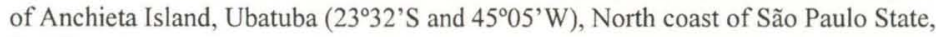
Brazil.

KEY WORDS. Crustacea, Decapoda, Brachyura, Xanthidae, Hexapanopeus heblingi sp.n., taxonomy
\end{abstract}

O gênero Hexapanopeus Rathbun, 1898 é representado na carcinofauna do litoral brasileiro por quatro espécies (MELo 1996), todas endêmicas para o Atlântico Ocidental. A espécie de maior amplitude latitudinal sul é H. schmitti Rathbun, 1930 que se estende desde o Ceará (Brasil) até o Uruguai e é a única que não se distribui no hemisfério norte. As outras três espécies: H. paulensis Rathbun, 1930; H. caribbaeus (Stimpson, 1871) e H. angustifrons (Benedict \& Rathbun, 1891), distribuem-se nos dois hemisférios, sendo a última a de maior alcance latitudinal $\left(40^{\circ} \mathrm{N}\right.$ até $\left.30^{\circ} \mathrm{S}\right)$.

\section{MATERIAL E MÉTODOS}

Desenvolveu-se, durante vários anos, o cultivo de espécies dos gêneros Hexapanopeus Rathbun, 1898 e Panopeus H. Milne Edwards, 1834, visando o conhecimento das formas larvais e juvenis. Foram trabalhadas três espécies e em todas elas foi alcançado o estágio adulto.

A descrição desta nova espécie está baseada em adultos obtidos do cultivo em laboratório. Esta é uma situação inédita, pois as descrições de Decapoda Brachyura são baseadas em adultos obtidos na natureza. $\mathrm{O}$ primeiro e único exemplar, fêmea ovígera, desta espécie foi coletado na natureza, em Ubatuba, Estado de São Paulo. A partir das larvas que nasceram desta fêmea organizou-se uma linhagem que permitiu o estudo do desenvolvimento, até o estado adulto, de muitos machos e fêmeas. A fêmea ovigera mediu $8,0 \mathrm{~mm}$ de largura e $5,7 \mathrm{~mm}$ de comprimento, um pouco maior do que o holótipo (Figs 1,2), porém menor do que o parátipo fêmea (Figs 3,4).

1) Contribuição número 1056 do Departamento de Zoologia, Universidade Federal do Paraná.

2) Departamento de Biologia Animal e Vegetal, Universidade Estadual de Londrina. Caixa Postal 6001, 86051-990 Londrina, Paraná.

E.mail: misael@npd.uel.br

3) Departamento de Zoologia, Universidade Federal do Paraná. Caixa Postal 19020, 81531-990. Curitiba, Paraná. Bolsista do CNPq.

E.mail: jloyola@bio.ufpr.br 

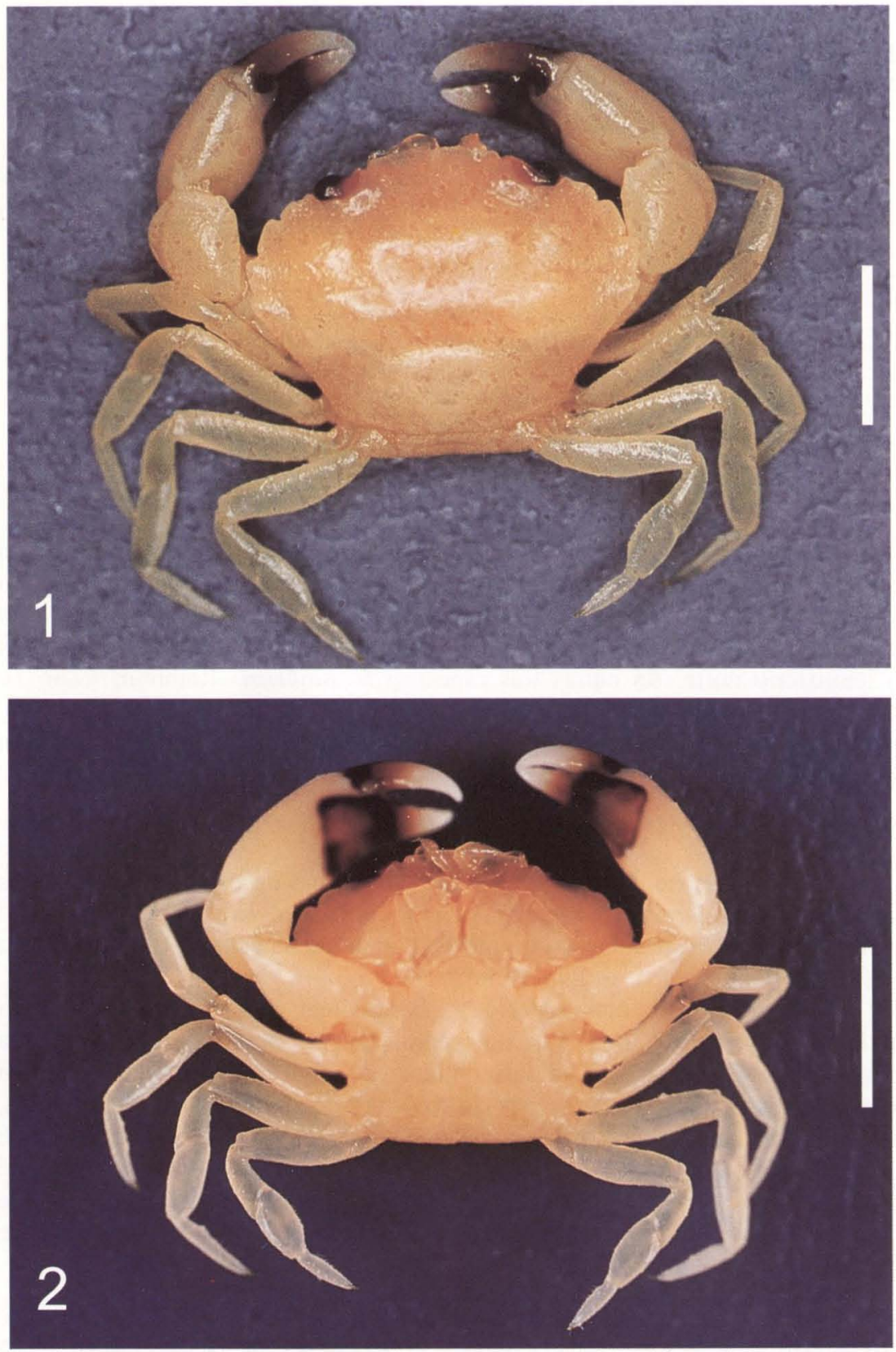

Figs 1-2. Hexapanopeus heblingi sp.n. holótipo macho. (1) Vista dorsal; (2) vista ventral. Escala: $3 \mathrm{~mm}$. 


\section{Hexapanopeus heblingi sp.n.}

Figs $1-20$

Diagnose. Largura da carapaça cerca de uma e meia vezes o comprimento. Fronte estreita, igual a 1/4 da largura da carapaça, com linha dupla de grânulos; dividida ao meio por sinus em forma de "V" e fracamente projetada para a frente. Pedúnculo ocular granulado na parte basal e com cerdas na margem anterior. Superfície dorsal da carapaça com linhas transversais de grânulos nas regiões protogástrica, mesobranquial e metabranquial; região mediana com um sulco em forma de "Y" invertido. Sulco da base do dente orbital até a região protogástrica. Primeiro e segundo dentes antero-laterais coalescidos e os outros três distintos. Dedos fixos e móveis com a metade basal escura e a distal clara; cor escura do dedo fixo avança sobre a palma. Dedo móvel do quelípodo direito com um dente distinto na face cortante proximal.

Descrição. Holótipo macho. Carapaça (Fig. 5). Com forma hexagonal, convexa, com largura de uma e meia vezes o comprimento. Superfícies dorsal e ventral revestidas de grânulos. Largura da fronte correspondente a 1/4 da largura da carapaça e levemente projetada para a frente, além da margem anterior do pedúnculo ocular; parte mediana com um entalhe, em forma de "V", que se prolonga, em sulco, até a região protogástrica e bifurca-se em "Y" invertido; margem anterior com duas linhas de grânulos (Fig. 6). Epístoma não visível dorsalmente; estreito e com projeção mediana que se dirige para a face ventral da fronte separando os pedúnculos das antênulas. Margem do epístoma granulada. Margens, superior e inferior, da órbita com grânulos; apesar de existir um dente nas margens inferior e superior internas, eles não se tocam e nem excluem a antena da órbita. Primeiro e segundo dentes ântero-laterais coalescidos, separados por sinus raso e largo; terceiro dente retangular, com margem posterior oblíqua e ponta voltada para frente; quarto dente triangular, com ápice agudo; quinto dente mais curto e menos largo que os anteriores e dirigido para fora. Margens póstero-lateral e posterior guarnecidas por finas cerdas. Regiões protogástrica e mesobranquial com linhas simples e metabranquial com linha dupla de grânulos (Figs 5,6).

Terceiro maxilípodo (Fig. 15). Coxopodito desenvolvido, revestindo a abertura branquial; com margem anterior densamente guarnecida de cerdas plumosas. Basipodito curto e triangular. Isquipodito o maior artículo, retangular, mais longo do que largo; apresenta na região mediana um sulco em todo o seu comprimento; ângulo basal interno com um tufo de cerdas e na mesma margem, subdistalmente, uma série de cerdas. Meropodito projetado em sua margem externa em ângulo obtuso; margem oposta com uma série de cerdas; superfície ventral, subdistalmente, uma leve concavidade, de fundo liso. Seguem três artículos: o carpopodito, o propodito e o dáctilopodito formando um palpo; dáctilopodito mais quitinizado que os outros dois e terminando em unha rígida; carpopodito e propodito com superfície ventral revestida por cerdas. Todo o maxilípodo com superfície granulosa. Exopodito constituído por um artículo basal, estreito e longo, com superfície ventral granulosa e margem interna superior com uma saliência subapical; flagelo tênue e multiarticulado. 

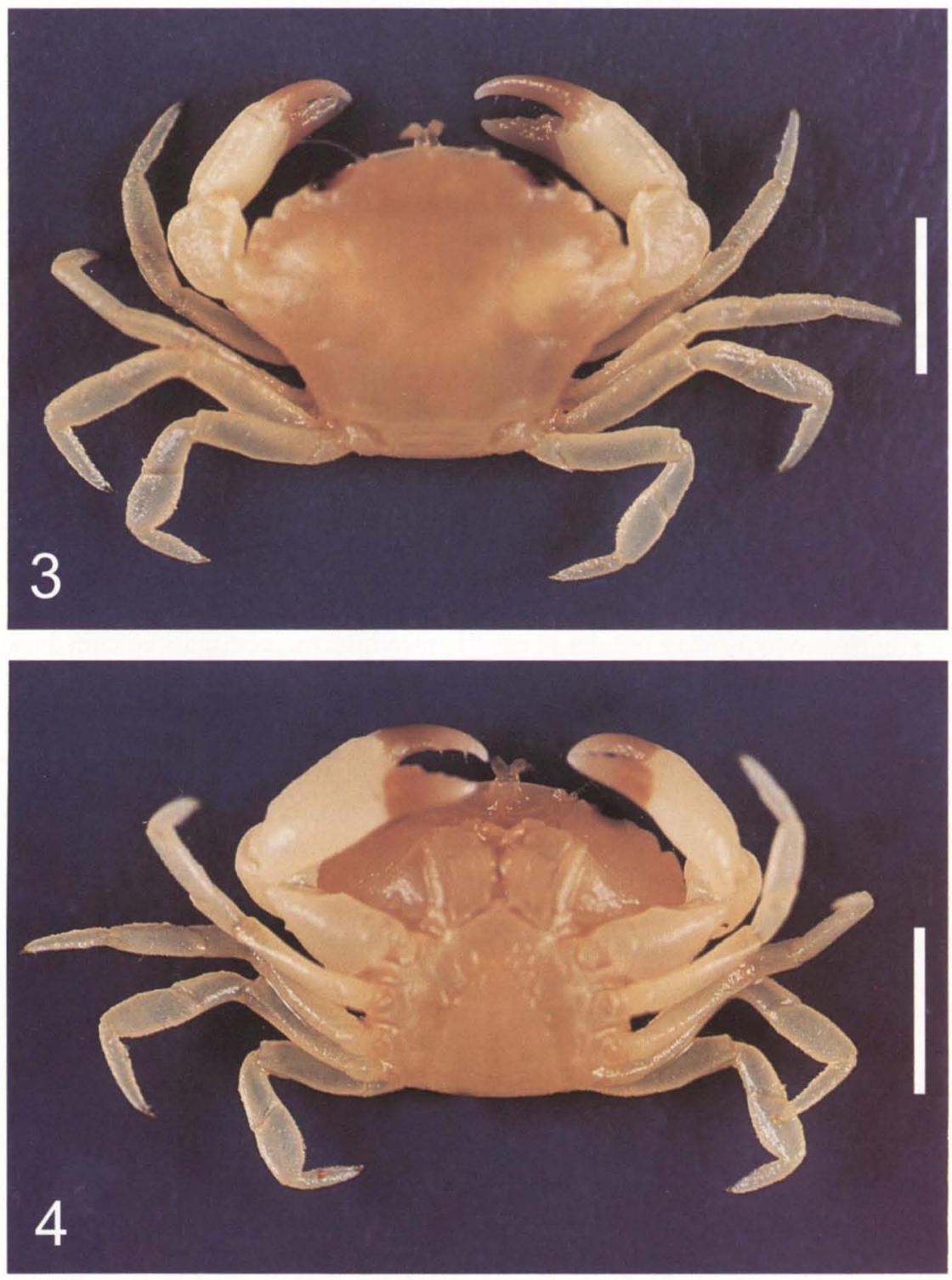

Figs 3-4. Hexapanopeus heblingi sp.n. parátipo fêmea. (3) Vista dorsal; (4) vista ventral. Escala: $3 \mathrm{~mm}$. 
Antênula (Figs 16, 17). Primeiro artículo peduncular globoso, fortemente esclerotizado e bem encaixado na cavidade antenular, não sendo visível dorsalmente; comprimento pouco maior do que o dobro do segundo artículo; largura cerca de três vezes a dos demais artículos; face anterior granulosa; margem articular com cerdas simples e plumosas. Segundo e terceiro artículos do pedúnculo estreitos, mais longos do que largos e de comprimentos subiguais; segundo artículo desprovido de cerdas; terceiro, com vários conjuntos de cerdas longas que guarnecem o endopodito distalmente, os maiores ultrapassam-no. Endopodito com duas partes distintas: a basal (Fig. 17) formada de 10 artículos curtos, que se dispõem da base para o ápice como uma pirâmide; de cada artículo sai um conjunto de estetos longos, que alcançam o ápice do endopodito, e que se dispõem de modo linear; a outra parte do endopodito assemelha-se a um flagelo e é composta por seis artículos estreitos, providos de cerdas simples. Exopodito triarticulado e provido de cerdas curtas e simples (Fig. 16).

Antena. Inclusa, em encaixe, na cavidade orbital; com três artículos pedunculares: primeiro artículo, em forma de paralelepípedo, mais longo que largo, com dentes na região apical interna, algumas cerdas plumosas na região distal e recoberto por grânulos esparsos. Segundo e terceiro artículos estreitos e mais curtos do que o primeiro; com um par de cerdas aculeadas plumosas e distintas na margem interna da região apical. Segundo artículo recoberto, dorsalmente, por grânulos esparsos. Flagelo com 17 artículos mais estreitos e curtos do que aqueles do pedúnculo; somente o primeiro artículo é desprovido de cerdas.

Pereópodos (Figs 8-14). Quelípodo com superfície granulosa, exceto nos dedos fixo e móvel (Fig. 8); mero (Fig. 13) curto, robusto e com faces interna e externa granulosas; margem superior recoberta por cerdas e região distal, próximo à articulação carpodial, com um profundo e distinto sulco. Carpo (Figs 8, 14), com um tubérculo granuloso na face interna, próximo à articulação propodial, margem externa distal com um sulco em sentido longitudinal. Própodo com um sulco longitudinal na face superior, que se estende desde a articulação carpodial até a base do dedo móvel; este sulco é provido de uma carena de grânulos em cada margem (Fig. 8). Dedo móvel com poucos grânulos na face superior; dedos móvel e fixo (Figs 11,12) apresentam na metade proximal uma coloração escura; a coloração do dedo fixo avança cerca de $1 / 4$ do comprimento da palma; porção basal do dedo móvel do quelípodo direito com forte dente rombudo; dentes da face cortante dos dedos móvel e fixo do quelípodo direito, mais pronunciados. Quelípodos assimétricos, sendo o direito maior (Figs 8, 11). Pereópodos com poucas cerdas (Figs 8-10).

Abdome (Fig. 7). Primeiro somito abdominal um pouco mais largo do que os demais; segundo estreito e curto; terceiro, quarto e quinto somitos, do macho, fusionados, de forma trapezoidal, e com comprimento duas e meia vezes o do sexto somito. Telso triangular. Superfície dorsal do abdome recoberta por grânulos, com margens providas de cerdas curtas e densas.

Gonópodo I (Figs 18, 19). Estreito e longo, atingindo o ápice do telso; porção proximal guarnecida de muitas cerdas plumosas; base com uma abertura distinta que corresponde ao início do canal gonopodial, com margens providas de cerdas plumosas e simples; esse canal alonga-se até a base do processo mediano. Gonópodo 

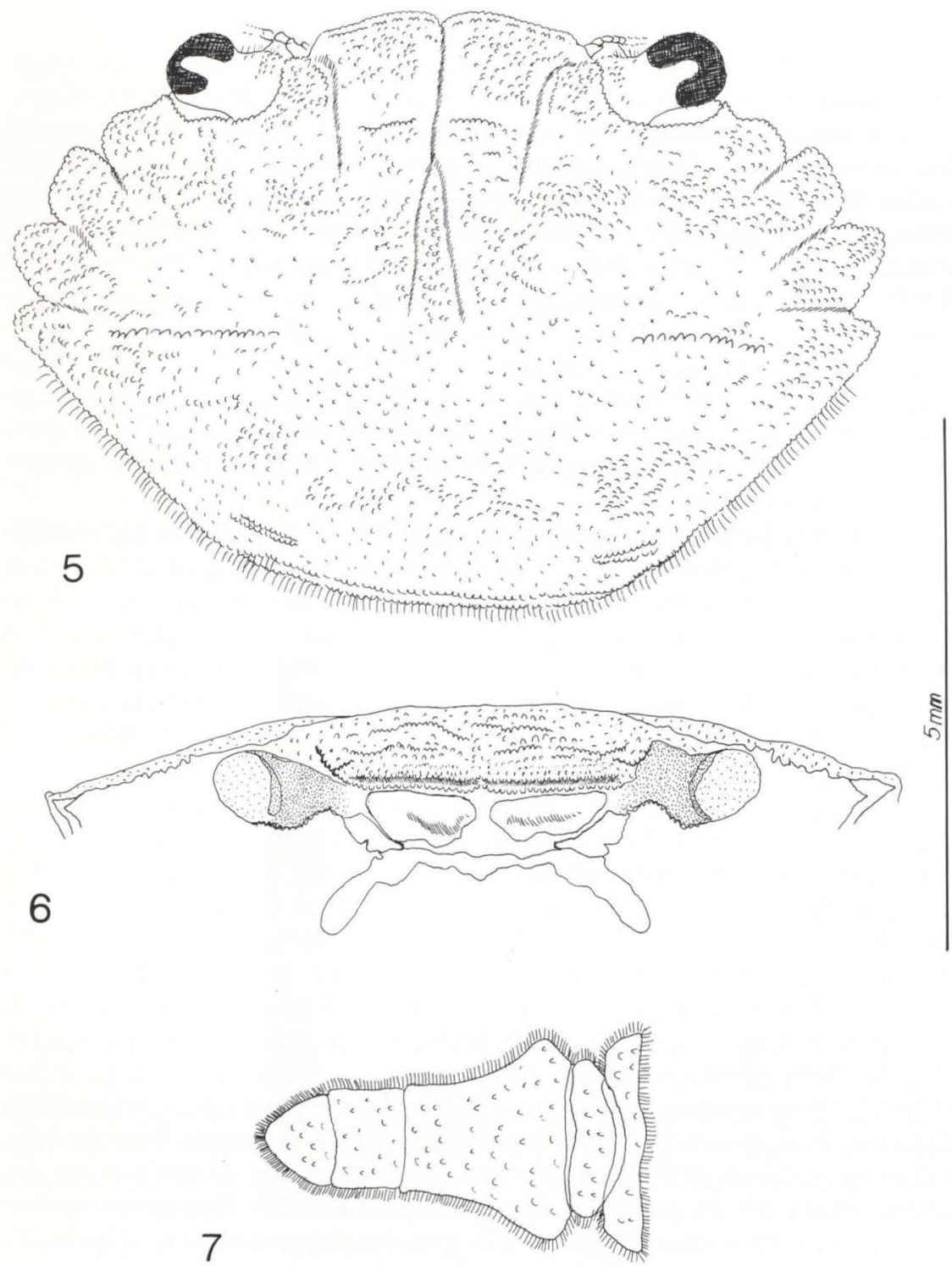

Figs 5-7. Hexapanopeus heblingi sp.n. holótipo macho. (5) Carapaça, vista dorsal; (6) carapaça, vista frontal; (7) abdome.

com duas linhas suturais, em todo o seu comprimento: uma mesial e outra lateral e entre elas uma série de espinhos curtos. Processo caudal com sete a nove espinhos, dispostos em linha, número variável entre os gonópodos esquerdo e direito. Processo mediano com ápice triangular, revestido de cerdas minúsculas, e margens laterais com dentículos. Margem externa do gonópodo, subapicalmente, com dois espinhos 


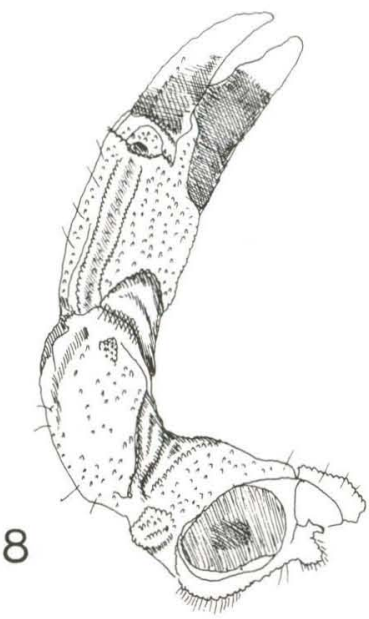

(PII)

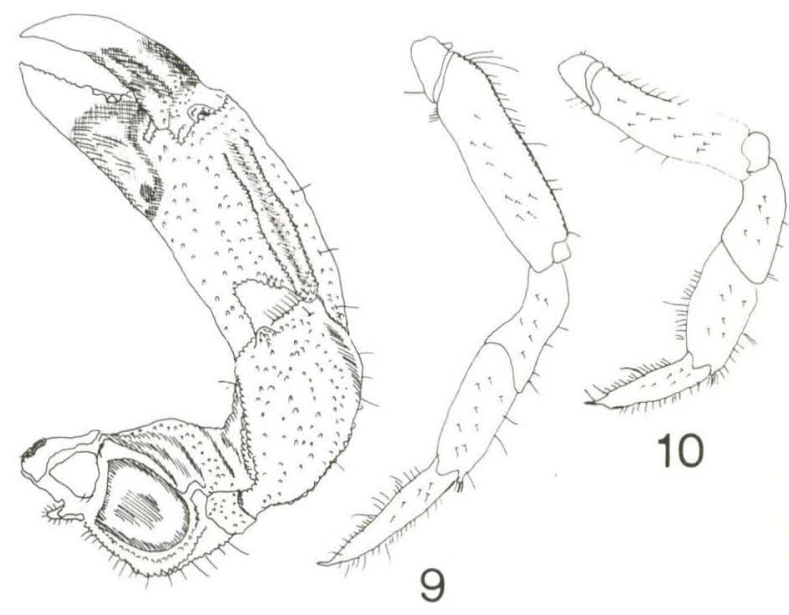

(19)

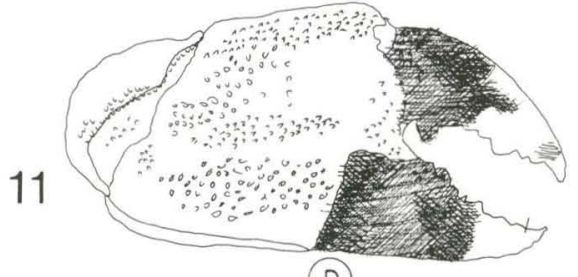

(D)

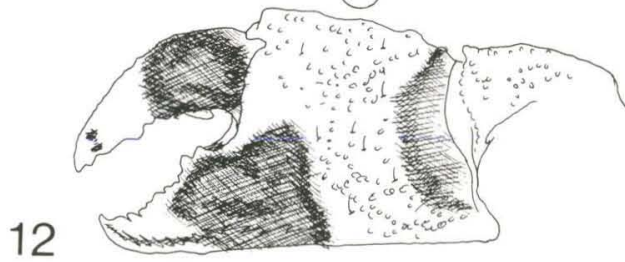

(D)

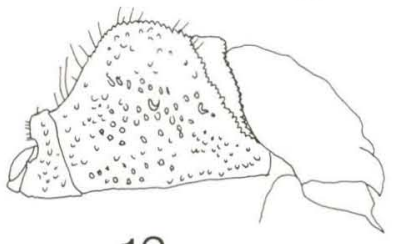

13
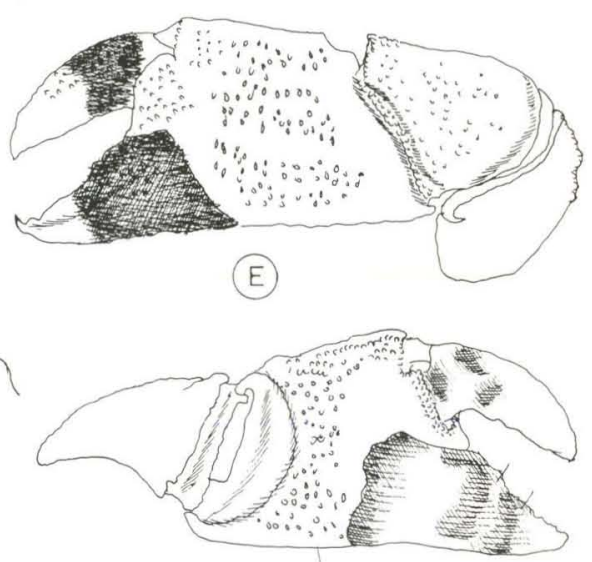

(E)

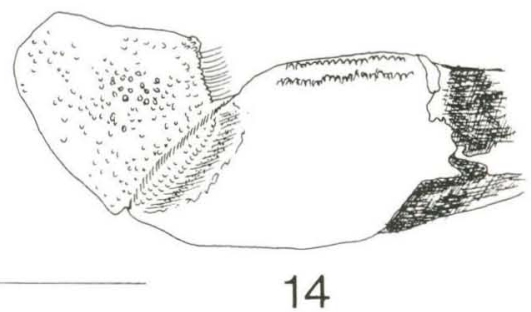

Figs 8-14. Hexapanopeus heblingisp.n. holótipo macho. (8) Quelipodos. $P_{1} E$, esquerdo; $P_{1} D_{\text {, }}$ direito; (9) pereópodo III; (10) pereópodo V; (11) quelipodos. Palma, face externa; (12) quelipodos. Palma, face interna; (13) quelípodo direito, meropodito, face externa; (14) quelípodo direito, carpo, face externa. (D) Direito, (E) esquerdo. 


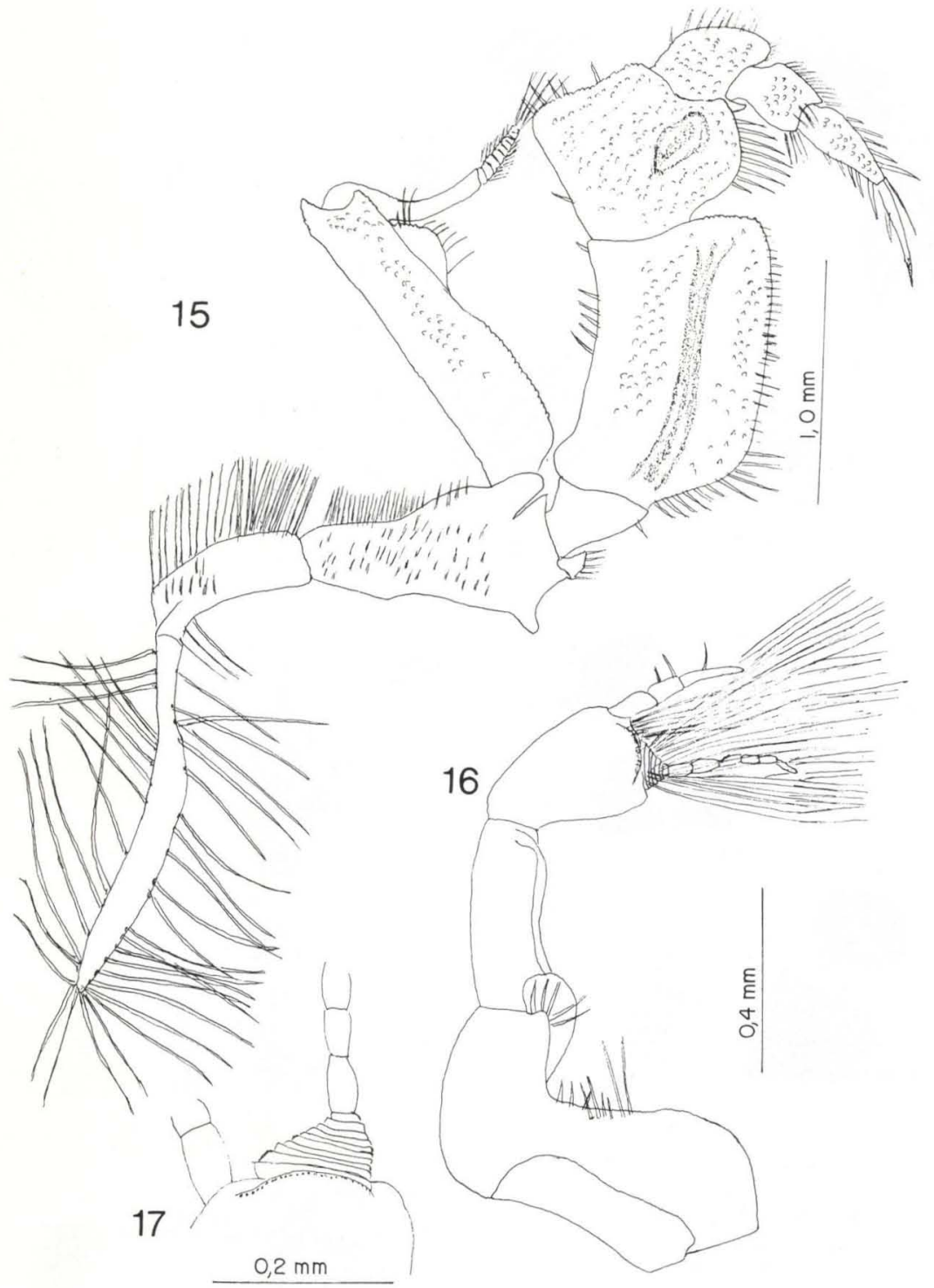

Figs 15-17. Hexapanopeus heblingi sp.n. holótipo macho. (15) Maxilipodo III; (16) antênula; (17) antênula, detalhe do endopodito.

e seis cerdas longas e simples. Ápice do processo mediano alcançando a base do processo acessório. Este processo é semi-circular, assemelhando-se a um capuz que engloba o processo mediano; com três espinhos nítidos, na região mediana. Face mesial do gonópodo com um único dente lateral, simples e forte, triangular e pouco 
projetado. Margem lateral do gonópodo provida, subapicalmente, de cerdas; abaixo desta região há cerdas pequenas e esparsas. Face mesial, medianamente, com uma fileira de espinhos em sentido longitudinal.

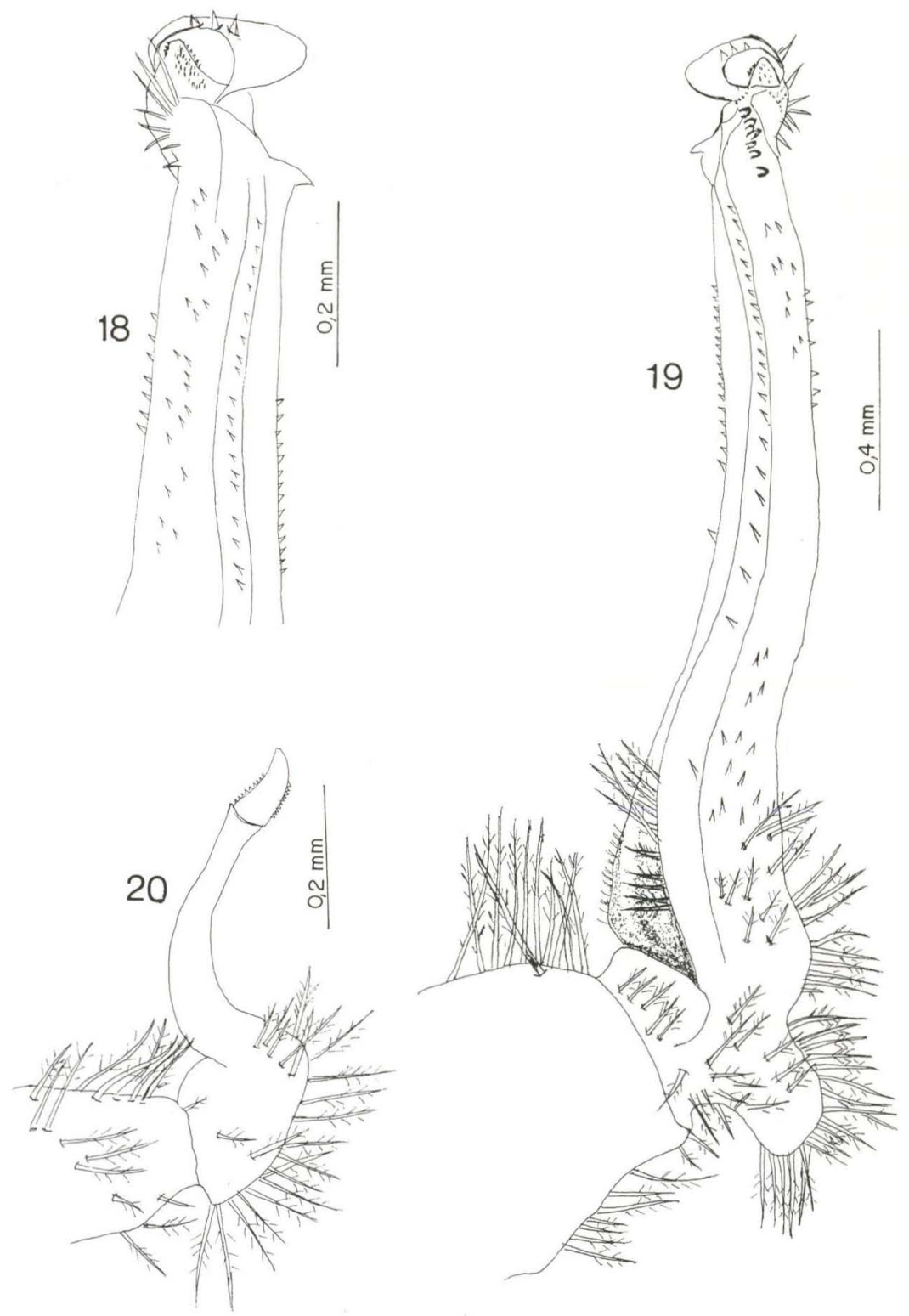

Figs 18-20. Hexapanopeus heblingi sp.n. holótipo. (18) Gonópodo I esquerdo, face dorsal; (19) gonópodo I esquerdo, face ventral; (20) gonópodo II esquerdo, face ventral. 
Gonópodo II (Fig. 20). Artículos basais revestidos de cerdas plumosas e longas; corpo constituído de uma haste, longa e estreita, isenta de cerdas e espinhos; flagelo curto, afilando-se em direção ao ápice e provido de espinhos nas margens mesial e lateral.

Medidas (mm). Holótipo macho - largura da carapaça: 7,74; comprimento: 5,16. Parátipo fêmea - largura da carapaça: 8,51 ; comprimento: 6,10 .

Coloração. Os espécimes in vivo possuem o corpo amarelo palha; in vitro, preservados em uma mistura de álcool e glicerina, na proporção de $1: 1$, a coloração original permanece, porém, com tonalidade mais clara. Alguns exemplares perdem a cor escura dos dedos móvel e fixo, permanecendo a coloração castanho claro, em ambos os quelípodos. A coloração dos dedos fixos do quelípodo dos machos (Figs 11,12 ), avança na palma, tanto interna como externamente, bem mais do que nas fêmeas.

Habitat. Fundo arenoso, a $15 \mathrm{~m}$ de profundidade.

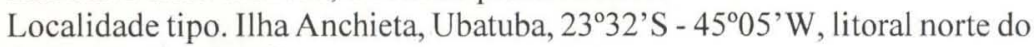
estado de São Paulo, Brasil.

Variações Intraespecíficas. Processo caudal do gonópodo I com número de espinhos laterais variando de 7 a 9; pode haver também, variação quanto ao número desses espinhos entre os gonópodos direito e esquerdo de um mesmo indivíduo. Num mesmo estágio de desenvolvimento, podem aparecer variações amplas na largura e no comprimento da carapaça. Nos machos, a largura variou de $3,69 \mathrm{~mm}$ a $7,94 \mathrm{~mm}$ e o comprimento variou de $2,77 \mathrm{~mm}$ a $4,19 \mathrm{~mm}$. Nas fêmeas a menor largura de carapaça foi de $3,81 \mathrm{~mm}$ e a maior de $10,06 \mathrm{~mm}$ e o comprimento variou entre $2,77 \mathrm{~mm}$ a $7,06 \mathrm{~mm}$.

\section{DISCUSSÃO}

As espécies de Hexapanopeus caracterizam-se pelo tamanho reduzido. Morfologicamente, $H$. hebling $i$ sp.n. assemelha-se a $H$. schmitti mas, distingue-se por apresentar dupla linha de grânulos na margem frontal; por não possuir tubérculo largo na região sub-hepática; por possuir um sulco em "Y" invertido partindo do sinus frontal e terminando na região metagástrica; a granulação da carapaça é diferente nas duas espécies; há diferença, também, na conformação do terceiro somito do abdome do macho.

Ultimamente, tem sido dada muita importância à estruturação do gonópodo I, que se constitui em importante embasamento de valor taxonômico. SMALEY (1964) propôs uma terminologia para o gonópodo I; GUINOT (1978) enfatizou a importância do gonópodo I nos Xanthidae; MARTIN \& ABELE (1982) e MAGALHÃES \& TÜRKAY (1996) realizaram estudos comparativos sobre o gonópodo I e ainda, os últimos autores atualizaram a terminologia utilizada para este apêndice.

O gonópodo I de $H$. heblingi sp.n. é bastante diferente dos gonópodos de $H$. angustifrons, de H. beebei Garth, 1961, constante do trabalho de MARTIN \& ABELE (1982) e de H. paulensis, figurado por WiLLIAMS (1965). O autor senior fez estudo de parátipos de $H$. schmitti depositados na Coleção Carcinológica do Museu de Zoologia da Universidade de São Paulo, Brasil, e constatou que na conformação geral, seus gonópodos se assemelham aos de $H$. heblingi sp.n., ocorrendo, no 
entanto, diferenças importantes. Em H. heblingi sp.n., o processo mediano não ultrapassa a margem inferior do processo acessório e em $H$. schmitti sp.n. ultrapassa a margem inferior do referido processo; o número de espinhos em $H$. heblingi sp.n., no processo acessório, é menor do que o da outra espécie. Há também, diferenças quanto ao número de espinhos e cerdas na região subapical.

Além dessas diferenças, o estudo do desenvolvimento larval (em andamento) ofereceu um melhor embasamento para a instituição de $H$. heblingi sp.n. como uma espécie nova para a ciência.

As menores medidas foram tomadas de exemplares machos e fêmeas do sexto estágio de desenvolvimento, após a megalopa, quando os exemplares adquiriram os caracteres sexuais secundários, amplamente utilizados em trabalhos de taxonomia. Os maiores machos pertenciam ao décimo estágio de desenvolvimento e as fềmas ao décimo segundo estágio.

Etimologia. O nome da espécie foi dedicado ao Prof. Dr. Nilton José Hebling, do Departamento de Zoologia, Universidade Estadual Paulista "Júlio de Mesquita Filho", Rio Claro, eminente carcinólogo, que deu início aos estudos de desenvolvimento pós-embrionário de Brachyura e Anomura no Brasil.

Registro. O holótipo macho, parátipo fêmea e o lote de parátipos (quatro machos e quatro fêmeas) estão registrados, respectivamente, sob os números: MZUSP 12.281; MZUSP 12.282 e MZUSP 12.283 e depositados na coleção carcinológica do Museu de Zoologia da Universidade de São Paulo, São Paulo, Brasil.

AGRADECIMENTOS. Este trabalho é parte da Tese de Doutorado, do primero autor, desenvolvido junto ao Curso de Pós-Graduação em Ciências Biológicas, área de Zoologia, da Universidade Federal do Paraná, a quem agradecemos todas as facilidades laboratoriais que nos foram prestadas.

\section{REFERÊNCIAS BIBLIOGRÁFICAS}

GuINOT, D. 1978. Principes d'une classification évolutive des crustacés décapodes brachyoures. Bull. Biol. France Belgique 112: 211-292.

MAGALHÃES, C. \& M. TÜRKAY. 1996. Taxonomy of the neotropical freshwater crab family Trichodactylidae. I. The generic system with description of some new genera. Senckenb. biol. 75 (1/2): 63-95.

MARTIN, J.W. \& L.A. AbELE. 1982. Notes on male pleopod morphology in the brachyuran crab family Panopeidae Ortmann 1893, sensu Guinot (1978) (Decapoda). Crustaceana 50 (2): 182-198.

MELo, G.A.S. 1996. Manual de identificação dos Brachyura (Caranguejos e Siris) do litoral brasileiro. São Paulo, Editora Plêiade/Fapesp, 604p.

SMALEY, A.E. 1964. A terminology for the gonopods of a american river crabs.

Syst. Zool. 13 (1): 28-31.

Williams, A.B. 1965. Marine decapod crustaceans of the Carolinas. Fish. Bull. 65 (1): 1-298.

Recebido em 27.III.1997; aceito em 06.V.1998. 